\title{
Axonal Transport and Distribution of Endogenous Calcitonin Gene-Related Peptide in Rat Peripheral Nerve
}

\author{
Y. Kashihara, M. Sakaguchi, and M. Kuno \\ National Institute for Physiological Sciences, Okazaki 444, Japan
}

Calcitonin gene-related peptide (CGRP) has been found in both sensory and motor neurons. It has been suggested that CGRP is transported from neuron cell bodies to their terminals, where it may act as an anterograde trophic factor. However, it is not known how fast CGRP is transported or whether CGRP found in the innervated target organ indeed originated in neural tissues. We have quantified endogenous CGRP in the rat peripheral nerve by a newly developed enzyme immunoassay. The CGRP immunoreactive material obtained from neural tissues coincided with synthetic rat CGRP in fractional distrlbutions separated by gel filtration. After ligation of the sciatic nerve, tissue CGRP accumulated in the segment central to the ligature. The rate of anterograde transport of CGRP was about $1 \mathrm{~mm} / \mathrm{hr}$ in both sensory and motor fibers. In the sciatic nerve, only a small fraction of CGRP measured was found to originate from the motor nerve fibers. This may be due in part to the disproportionately large number of sensory fibers in the sciatic nerve and in part to the possible presence of CGRP in sympathetic nerve fibers. The CGRP content in the dorsal root fibers was significantly lower than that in the peripheral processes of the sensory neurons. The CGRP content in the hind leg muscle was much higher than that expected from the amount of CGRP per nerve fiber in the sciatic nerve. Most CGRP in muscle disappeared following denervation. It is concluded that CGRP highly concentrated in nerve terminals is supplied by axonal transport from the neuron cell bodies.

Calcitonin gene-related peptide (CGRP) was initially determined to be encoded by alternative processing of the RNA transcript from the calcitonin gene (Amara et al., 1982). Subsequently, the presence of CGRP has been demonstrated in a variety of central and peripheral neurons by immunoreactivity with antisera against synthetic CGRP (Rosenfeld et al., 1983; Gibson et al., 1984; Wiesenfield-Hallin et al., 1984; Kawai et al., 1985; see review by Zaidi et al., 1987). CGRP immunoreactivity can be seen in motor nerve terminals (Rodrigo et al., 1985; Takami et al., 1985a, b; Matteoli et al., 1988), as well as in spinal motoneurons (Rosenfeld et al., 1983; Gibson et al., 1984; New and Mudge, 1986). Thus, CGRP apparently coexists

Received Jan. 1, 1989; revised Mar. 14, 1989; accepted Mar. 15, 1989.

This work was supported by research grants from the Ministry of Education, Science and Culture of Japan. We wish to thank Dr. Kyozo Hayashi and his colleagues for detailed instructions for the 2-site enzyme immunoassay technique. We are also grateful to Ms. K. Ito and Ms. K. Oishi for their excellent technical assistance.

Correspondence should be addressed to Motoy Kuno, Department of Physiology, Kyoto University Faculty of Medicine, Kyoto 606, Japan.

Copyright (C 1989 Society for Neuroscience $0270-6474 / 89 / 113796-07 \$ 02.00 / 0$ with the classic transmitter $\mathrm{ACh}$ in motor nerve terminals. However, CGRP immunoreactivity in the nerve terminal appears to be confined within large dense-core vesicles, whereas $\mathrm{ACh}$ is present within small clcar vesicles (Mattcoli ct al., 1988).

Although neuromuscular transmission is not affected by the acute or chronic application of CGRP (Tsujimoto and Kuno, 1988), CGRP increases the synthesis of ACh receptors (Fontaine et al., 1986, 1987; New and Mudge, 1986) and intracellular cAMP in muscle (Takami et al., 1986; Laufer and Changeux, 1987; Kobayashi et al., 1987; Eusebi et al., 1988). Also, externally applied CGRP has been shown to alter the rate of desensitization of ACh receptors (Mulle et al., 1988) or the receptor channel conductance (Eusebi et al., 1988). Functional modulation of the $\mathrm{ACh}$ receptor by CGRP appears to be mediated by protein kinase, which regulates phosphorylation of the receptor molecule (Mulle et al., 1988; Hopfield et al., 1988). Furthermore, CGRP suppresses disuse-induced sprouting of motor nerve terminals (Tsujimoto and Kuno, 1988). Thus, CGRP may be released from motor nerve terminals and act as an anterograde trophic factor that may be involved in the regulation of synthesis of particular proteins in muscle (Fontaine et al., 1986; Changeux et al., 1987).

CGRP immunoreactivity in the cell bodies of motor and sensory neurons is known to be enhanced when cytoskeletal systems are impaired by treatment with colchicine (Gibson et al., 1984; $\mathrm{Ju}$ et al., 1987). This implies that CGRP may be synthesized in the cell bodies and transported in the somatofugal dircetion in both motor and sensory neurons. In fact, anterograde transport of CGRP has recently been demonstrated in the autonomic nerve (Varro et al., 1988). Here we report the distribution and axonal transport of CGRP measured in the somatic motor and sensory nerve fibers. The results show that endogenous CGRP is transported by anterograde axoplasmic flow at a rate of about $1 \mathrm{~mm} / \mathrm{hr}$ in both motor and sensory fibers and that the majority (95\%) of CGRP highly concentrated in muscle disappears after denervation.

\section{Materials and Methods}

Preparation. Adult Wistar rats were anesthetized with pentobarbital sodium (50 mg/kg, i.p.) or ether. The sciatic nerve was exposed and ligated with 8-0 silk suture at the midthigh level. The sciatic nerve was excised 1-24 hr later. Consecutive 2-mm segments of the excised nerve central and peripheral to the ligature were cut on dry ice and stored at $-80^{\circ} \mathrm{C}$ until requircd for the assay. Individual frozen nerve segments were homogenized with a glass-glass homogenizer in $10 \mathrm{~mm}$ PBS (pH 7.0). The homogenates were centrifuged for $10 \mathrm{~min}$ at $10,000 \mathrm{~g}$, and the supernatants were mixed immediately with BSA $(0.1-0.5 \%)$. In other experiments, the hind leg muscle was prepared similarly to measure its CGRP content. The muscle was homogenized by sonication.

To assess the distribution of CGRP in motor and sensory fibers, the CGRP content was measured in the lumbar ventral and dorsal roots 


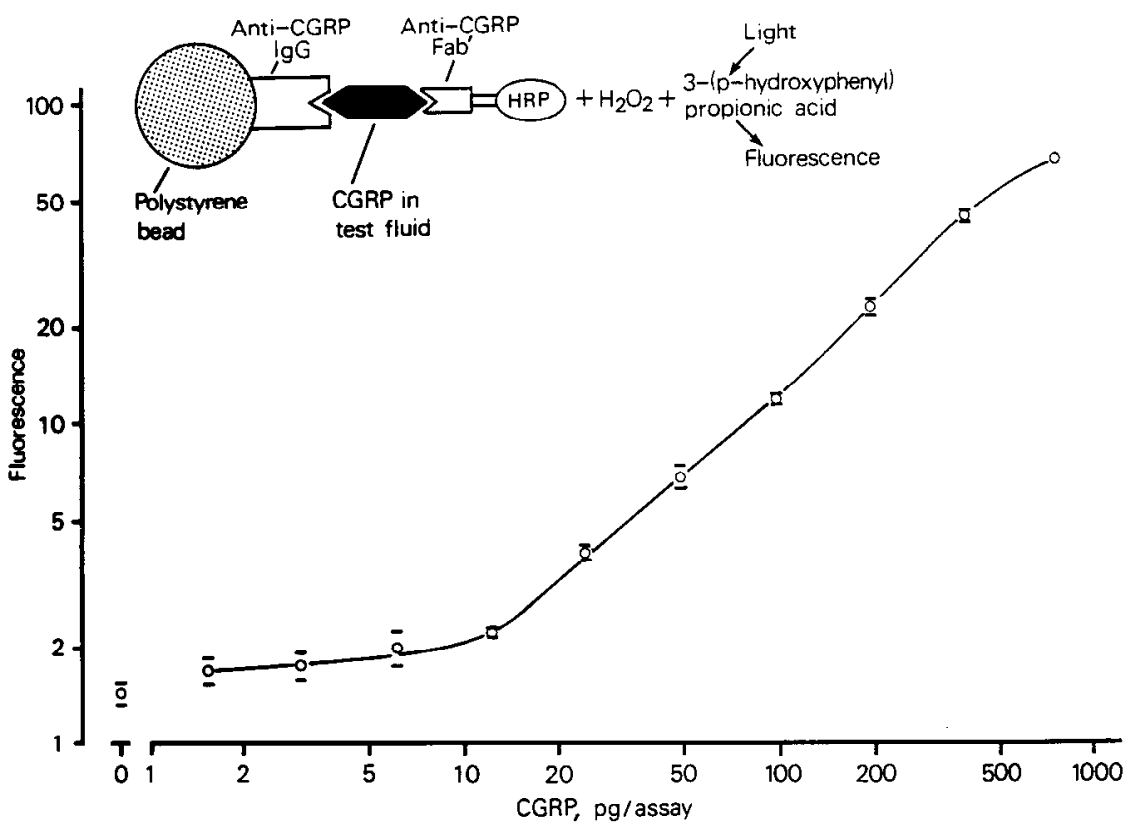

Figure 1. The procedure and sensitivity of a 2-site enzyme immunoassay of CGRP. Top, A schematic diagram of the assay rudiments. Anti-CGRP IgG coated on polystyrene beads acts as a first site to bind to CGRP in a given test solution. Anti-CGRP Fab' conjugated to HRP acts as a second site to bind CGRP. The enzyme reaction of HRP was induced by the addition of hydrogen peroxide. The enzyme reaction was quantified by the fluorescence intensity. Bottom, A standard assay curve is shown as a function of the CGRP concentration. Horizontal bars, $\mathrm{SD}$ in 3 tests. separately. Axonal transport of CGRP was examined in the sciatic nerve after degeneration of motor or sensory fibers. Thus, the ventral roots from the 4th through 6th lumbar segments were sectioned on the left side in one group of rats. Similarly, in another group of animals, the dorsal root ganglia in the same lumbar segments were unilaterally removed. Seven to $11 \mathrm{~d}$ after these operations, the sciatic nerves on the experimental side as well as on the contralateral, control side were ligated at the midthigh level. CGRP accumulated in ligated nerves was measured $24 \mathrm{hr}$ later.

Anti-CGRP antibodies. The antiserum was raised in rabbits by injecting synthetic rat $\alpha$-CGRP (Peptide Institute, Inc.) emulsified with Freund's complete adjuvant. The antiserum was then passed through a Protein A Sepharose CL-4B column (Pharmacia Fine Chemicals), and the IgG fraction was eluted from the column as described by Furukawa et al. (1983). The antibodies to CGRP were purified by affinity chromatography, using rat $\alpha$-CGRP linked to $\mathrm{CNBr}$-activated Sepharose $4 \mathrm{~B}$ (Pharmacia Fine Chemicals). The antibodies were eluted from the loaded column with $0.1 \mathrm{M}$ glycine- $\mathrm{HCl}(\mathrm{pH} 2.3)$ and immediately neutralized with $1 \mathrm{M}$ Tris. However, this fraction apparently was contaminated by some CGRP that might have leaked through the column together with the antibodies during elution. Contaminated CGRP was removed by dialysis of the eluate with ultrafiltration membranes (PM-10, Amicon $\mathrm{Co}$.) in the presence of $0.1 \mathrm{M}$ glycine- $\mathrm{HCl}(\mathrm{pH} 2.3)$, followed by replacement with $0.05 \mathrm{M}$ Tris- $\mathrm{HCl}(\mathrm{pH} 8.5)$.

Enzyme immunoassay. The procedure of our 2-site enzyme immunoassay was similar basically to that previously used for assay of NGF (Korsching and Thoenen, 1983; Furukawa et al., 1983). The rudiments of the assay are schematically illustrated at the top of Figure 1 (for technical details, see Furukawa et al., 1983; Kurobe et al., 1985, 1986). Briefly, polystyrene beads $(3.2 \mathrm{~mm}$ in diameter) were used as a solid phase to be linked to the affinity-purified antibodies against CGRP. The beads were incubated in $0.05 \mathrm{~m}$ Tris- $\mathrm{HCl}(\mathrm{pH} \mathrm{8.5)}$ containing the antibodies $(0.1 \mathrm{mg} / \mathrm{ml})$ overnight at $4^{\circ} \mathrm{C}$. The beads were washed with buffer $\mathrm{A}$ solution $(0.1 \mathrm{~m} \mathrm{Na}-\mathrm{K}$ phosphate, $\mathrm{pH} 7.0$, containing $0.3 \mathrm{M}$ $\mathrm{NaCl}, 1 \mathrm{mM} \mathrm{MgCl}_{2}, 0.1 \% \mathrm{NaN}_{3}$, and $0.5 \% \mathrm{BSA}$; Furukawa et al., 1983) and stored in the same solution at $4^{\circ} \mathrm{C}$ until use. Individual antibodycoated beads were exposed to the test solution $(0.1 \mathrm{ml})$ diluted by 0.15 $\mathrm{ml}$ of buffer A solution overnight at $4^{\circ} \mathrm{C}$. CGRP bound to the beads was then assayed by the anti-CGRP Fab' linked to HRP. For this purpose, the antibody immunoglobulin fraction was treated with pepsin to prepare $F\left(a b^{\prime}\right)_{2}$ fragments, which were converted to $F^{\prime} b^{\prime}$ by reduction with 2 -mercaptoethylamine. The $\mathrm{Fab}^{\prime}$ was conjugated to HRP with $\mathrm{N}$-succinimidyl 4-(N-maleimidomethyl)cyclohexane-1-carboxylate. The beads were incubated in a $10 \mathrm{~mm}$ Na-K PBS (pH 7.0) containing the Fab'-HRP complex and BSA $(0.5 \%)$ overnight at $4^{\circ} \mathrm{C}$. The enzyme reaction of HRP bound to the bead was initiated by the addition of $\mathrm{H}_{2} \mathrm{O}_{2}(0.015 \%$, vol/vol) against 3-( $p$-hydroxyphenyl) propionic acid $(0.6 \%$, wt/vol) in $0.1 \mathrm{~m}$ Na-K PBS (pH 7.0; Kurobe et al., 1985). After incubation for $60 \mathrm{~min}$ at room temperature, the reaction was terminated by the addition of glycine- $\mathrm{NaOH}(0.1 \mathrm{M}, \mathrm{pH} 10.3)$. The reactant was quantified by the fluorescence intensity, excitation, and emission wavelengths, being 320 and $405 \mathrm{~nm}$, respectively. As the standard, the fluorescence intensity of $1 \mu \mathrm{g} / \mathrm{ml}$ quinine in $\mathrm{H}_{2} \mathrm{SO}_{4}(0.05 \mathrm{M})$ was used. Figure 1 shows an example of the standard assay curve for CGRP. The lower limit of reliable quantitative measurements varied from one batch of beads to another coated with the antibodies, ranging from $2 \mathrm{pg} /$ assay $(20 \mathrm{pg} / \mathrm{ml})$ to $12 \mathrm{pg} /$ assay. The sensitive batch of beads was selected for assay of the tissues that contained relatively low concentrations of CGRP.

To evaluate the degree of the possible loss of CGRP during isolation and measurements of tissue CGRP, a known amount of synthetic CGRP (150-320 pg) was added to the homogenate of a $2-\mathrm{mm}$ segment of the sciatic nerve immediately before centrifugation, and the total CGRP measured was compared with that measured for the same amount of tissues alone. In 4 experiments, the mean recovery rate of added CGRP was $0.60 \pm 0.08$ (SD). No correction was made for this possible loss of CGRP. Therefore, all the values of CGRP content presented in the results may be an underestimate of the true value by about $40 \%$. All values described in the text give the mean and its SD. The statistical analysis was made by 2 -tailed $t$ tests with the significance limit of $p<$ 0.05 .

Gel permeation chromatography. CGRP-immunoreactive material obtained from the tissue was characterized by gel filtration. A short segment of the sciatic nerve was heated at $95^{\circ} \mathrm{C}$ for $10 \mathrm{~min}$ in $1 \mathrm{M}$ acetic acid, homogenized, and centrifuged. Aliquots $(0.25 \mathrm{ml})$ of the supernatants were applied to a $1.1 \times 46.5 \mathrm{~cm}$ Sephadex G-50 superfine column (Pharmacia Fine Chemicals). The column was eluted with 1 M acetic acid at a rate of $3 \mathrm{ml} / \mathrm{hr}$. Eluates of each fraction collected were lyophilized and redissolved in $0.5 \mathrm{ml}$ of buffer A solution. The sample was then quantified for material immunoreactive to CGRP by enzyme immunoassay. The fractional distribution was compared with that obtained by gel filtration of synthetic rat $\alpha$-CGRP. The elution diagram of CGRP immunoreactive material derived from the sciatic nerve (Fig. $2 A$ ) was virtually identical to that of synthetic rat CGRP (Fig. $2 B$ ). The elution diagram was not affected by the amount of added CGRP in a range from 0.5 to $25 \mathrm{ng}$ examined. As noted previously (Cadieux et al., 1986; Varro et al., 1988), the tissue-derived CGRP immunoreactive material tended to have an additional hump in the elution diagram (Fig. $2 A$ ). However, in different experiments, the peak of tissue-derived CGRP invariably coincided with the peak of synthetic CGRP, and $81-88 \%$ of the applied amount of tissue-derived CGRP was found in the same fractions as synthetic CGRP.

Immunohistochemistry. Attempts were made to examine spatial distributions of CGRP along ligated nerves by immunohistochemistry. The tibial branch of the sciatic nerve was ligated with 8-0 silk suture, and 


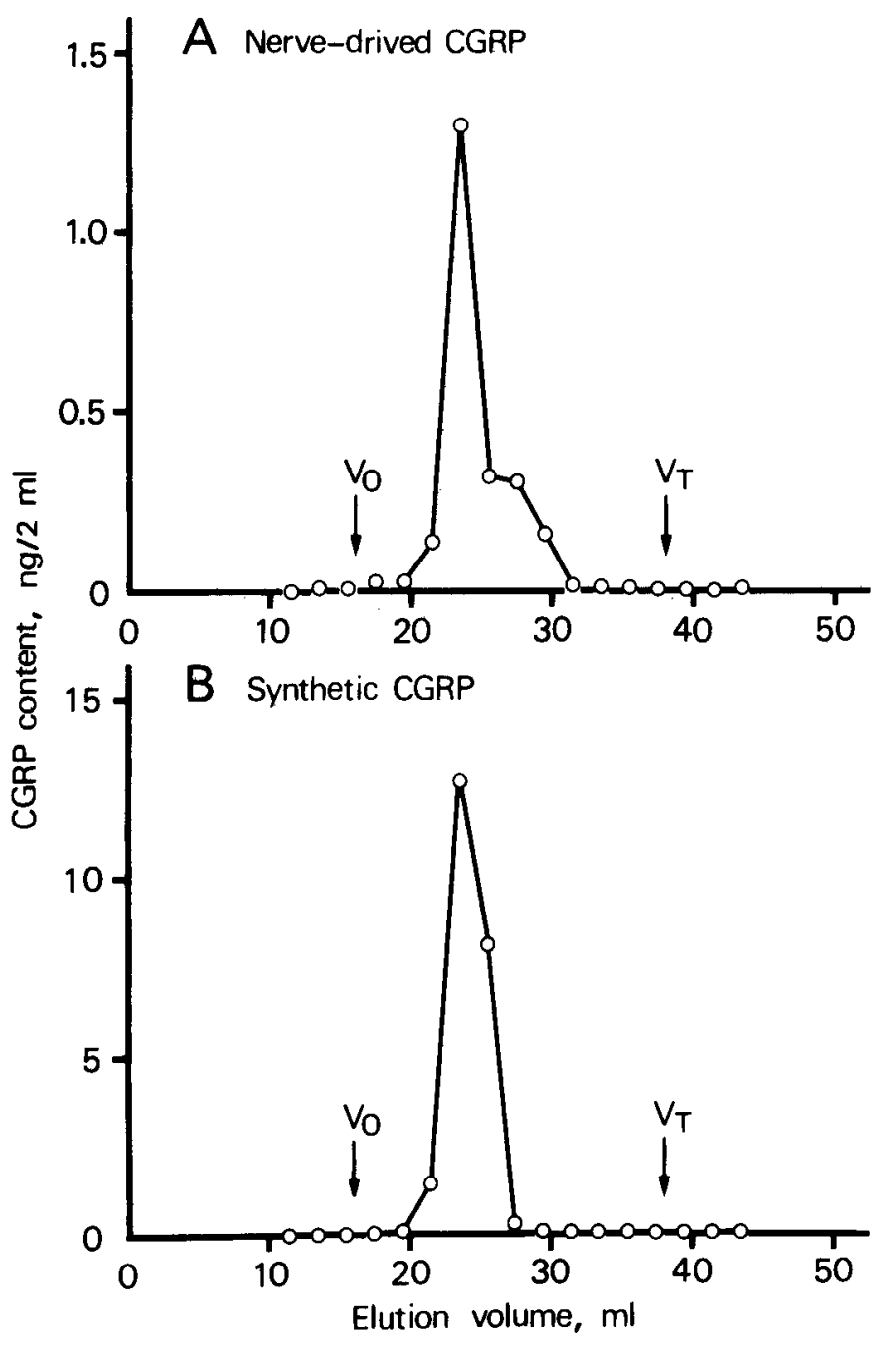

Figure 2. Elution diagrams of CGRP-immunoreactive material extracted from the sciatic nerve $(A)$ and synthetic rat CGRP $(B)$. Ordinates are the amount of CGRP measured by the enzyme immunoassay in each fraction tube $(2 \mathrm{ml}) . \mathrm{V}_{0}$, void volume; $\mathrm{V}_{\mathrm{T}}$, total volume.

$24 \mathrm{hr}$ later, the animal was anesthetized and perfused with $4 \%$ (wt/vol) paraformaldehyde in $0.1 \mathrm{M}$ PBS ( $\mathrm{pH} 7.4$ ). A segment of the tibial nerve, including the ligature, was sectioned longitudinally at $30 \mu \mathrm{m}$ on a freezing microtome. The specimen was pretreated with $10 \%$ newborn calf serum and reacted with anti-CGRP antisera overnight. The sections were then exposed to HRP-conjugated goat antirabbit IgG and stained with $3,3^{\prime}$-diaminobenzidine.

\section{Results}

Spatial distribution of CGRP in ligated nerves

If endogenous CGRP is transported by axoplasmic flow in the peripheral nerve, CGRP immunoreactive material is expected to accumulate progressively in the region abutting the site of ligation of the nerve. This possibility was examined qualitatively by immunohistochemistry on the tibial nerve $24 \mathrm{hr}$ after ligation. As shown in Figure 3, CGRP immunoreactivity was confined almost exclusively to a segment of the nerve immediately central to the ligature. Also, within this central segment, the density of immunoreactive material progressively decreased with the distance from the ligature. Thus, immunoreactivity was highly concentrated to a region about $0.5 \mathrm{~mm}$ from the ligature, and no reactive material was detected in segments more than $2 \mathrm{~mm}$ central to the ligature. Although the nerve segment peripheral to the ligature was clearly weaker in immunoreactivity than the central segment, some reactive patches were found distributed unevenly in the peripheral segment near the ligature. These results suggest that endogenous CGRP is transported largely, if not exclusively, in the anterograde (somatofugal) direction alung the peripheral nerve.

\section{The rate of axonal transport of CGRP}

The preceding observations were complemented by quantitative measurements of CGRP with the enzyme immunoassay. This assay was made $24 \mathrm{hr}$ after ligation of the sciatic nerve. Figure 4 shows the amount of CGRP measured in each of contiguous 2-mm segments central and peripheral to the site of ligation. In accordance with the immunohistochemical results, most of the accumulated CGRP was detected in the segment immediately central to the ligature. The amount of CGRP in this segment showed, on the average, a 6.4-fold increase compared with that measured in a $2-\mathrm{mm}$ segment of the contralateral, intact sciatic nerve. There was no significant accumulation of surplus CGRP in segments more than $2 \mathrm{~mm}$ central to the ligature. As suggested by immunohistochemistry (Fig. 3), there was a slight but significant accumulation of CGRP in the first 2-mm segment immediately peripheral to the ligature $(1.7$-fold), whereas the second peripheral segment contained less CGRP than the normal level $(0.4$-fold). Therefore, it is possible that some retrograde transport of CGRP may be present, in addition to its anterograde transport. However, since in the segment immediately peripheral to the ligature, CGRP immunoreactivity distributed unevenly (Fig. 3), this peripheral accumulation of CGRP could be artifactual. For example, if some microtubules were disrupted in the segment abutting the ligation, CGRP leaked from the highly accumulated region central to the ligature would be immobilized in the peripheral segment, thereby accumulating locally as uneven patches in spite of the presence of anterograde transport.

The amount of CGRP accumulated in the 2-mm segment immediately central to the ligature depended on the time after ligation. As shown in Figure 5 (at time 0), the mean CGRP content in a $2-\mathrm{mm}$ segment of the intact sciatic nerve was 204 $\pm 51 \mathrm{pg}(n=7)$, and the CGRP content in the central 2-mm segment increased linearly with time after ligation. From this relation, the rate of axonal transport of CGRP was estimated to be about $0.5 \mathrm{~mm} / \mathrm{hr}$.

\section{Transport of CGRP in motor and sensory fibers}

From the preceding results alone, it is not clear whether measured CGRP immunoreactive material originates from motor nerve fibers or sensory fibers or both. To address this question, we first measured the CGRP contents in the lumbar ventral and dorsal roots separately. The mean amount of CGRP found in a $2-\mathrm{mm}$ segment of the 4 th and 5 th lumbar ventral roots was $15 \pm 12 \mathrm{pg}(n=5)$ (Fig. $6 A$ and Fig. $7 B$ at time 0$)$. The mean amount of CGRP similarly mcasured in the 4 th and 5 th lumbar dorsal roots was $24 \pm 6 \mathrm{pg}(n=4)$ (Fig. $6 \mathrm{~A}$ ). Therefore, it seems clear that CGRP is present in motor nerve fibers as well as in sensory fibers. One might argue that CGRP measured in the ventral roots may originate from sympathetic preganglionic neurons. This possibility is unlikely, since CGRP immunoreactivity has not been detected in the lumbar intermediolateral column (Rosenfeld et al., 1983; Gibson et al., 1984).

About two thirds of the motor and sensory fibers in the lumbar 


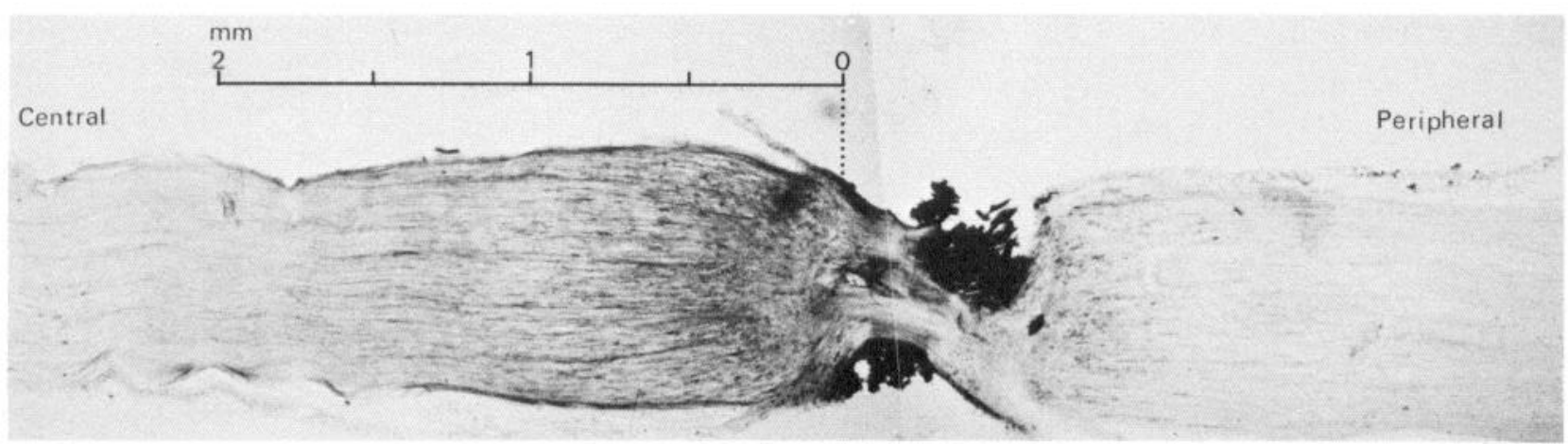

Figure 3. Histochemical CGRP immunoreactive profile in the tibial nerve, which had been ligated 24 hr previously. Calibration indicates the distance from the central border of constriction produced by the ligature. The silk suture used for ligation is seen around the constricted nerve. Note that immunoreactivity is largely confined to a segment of about $2 \mathrm{~mm}$ central to the ligature.

spinal roots constitute the sciatic nerve (Fig. 6B; see Discussion). However, the CGRP content in a 2-mm segment of the sciatic nerve (204 pg) (Fig. 6B; also see Fig. 5 at time 0 ) actually was much higher than the sum of CGRP found in 2-mm segments of the lumbar ventral and dorsal roots $(39 \mathrm{pg}$ ) (Fig. $6 A$ ). In order to examine this apparent paradox, the lumbar ventral roots were sectioned unilaterally or the lumbar dorsal root ganglia were removed on one side in chronic operations (see Materials and Methods). Seven to $11 \mathrm{~d}$ after these operations, the sciatic nerves were ligated on the contralateral, intact side as well as on the experimental side. The amount of CGRP accumulated in the 2 -mm segment immediately central to the ligature was then measured on both sides $24 \mathrm{hr}$ later. Figure $7 A$ shows the ratio

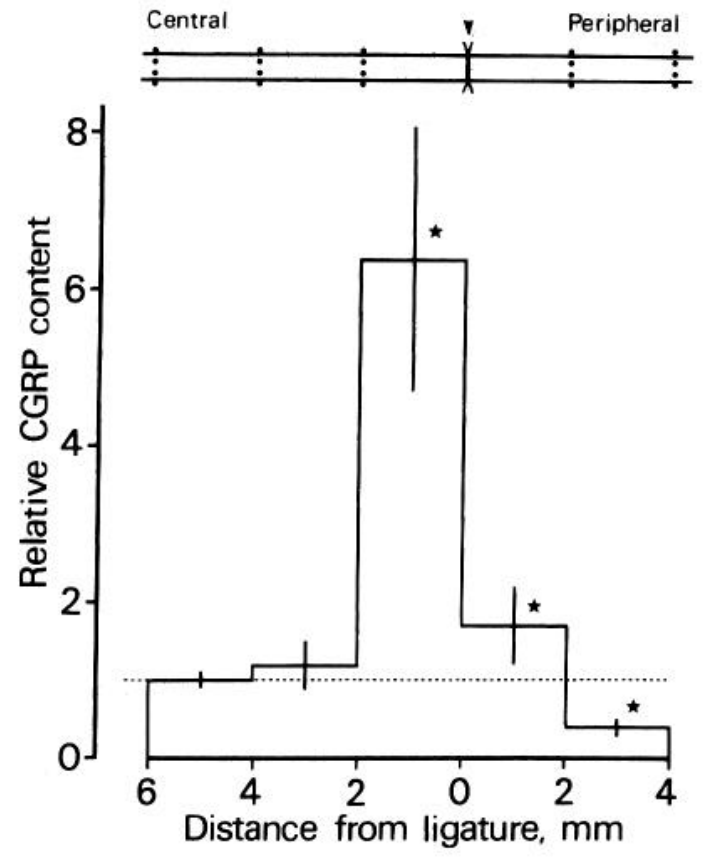

Figure 4. Changes in CGRP content in contiguous 2-mm segments central and peripheral to the ligature that had been applied to the sciatic nerve $24 \mathrm{hr}$ previously. Top, Sections of contiguous $2-\mathrm{mm}$ segments central and peripheral to the ligature (arrowhead). CGRP contents measured by the enzyme immunoassay are expressed relative to the CGRP content observed in a 2-mm segment of the contralateral, intact sciatic nerve. Vertical bars indicate $\mathrm{SD}(n=5)$. Asterisks indicate a significant difference from the CGRP content on the control side (interrupted line). of CGRP content measured on the experimental side to that on the intact side. After degeneration of motor fibers following section of the ventral roots, the amount of CGRP in the segment of the sciatic nerve $(111 \pm 12 \%, n=5)$ (Fig. $7 A$, column V) was not significantly $(0.20>p>0.10)$ different from the value measured on the control side. Since the number of motor fibers in the sciatic nerve is only about $10 \%$ of that of sensory fibers (Fig. 6B; also see Discussion), the expected decrease in the CGRP content of the sciatic nerve after degeneration of the motor fibers might not be detected. After degeneration of sensory nerve fibers induced by removal of the dorsal root ganglia, the amount of CGRP in the segment of the sciatic nerve was $48 \pm 17 \%$ ( $n=$ 5 ) of that found on the control side (Fig. $7 A$, column $D$ ). This decrease was highly significant $(p<0.001)$. Thus, CGRP immunoreactive material measured in the sciatic nerve originates mainly from the sensory fibers rather than from the motor fibers. However, a relatively large amount of CGRP (about $50 \%$ of the control level) was still present in the sciatic nerve following degeneration of sensory fibers (Fig. $7 A$, column $D$ ). The source of this remaining CGRP could be postganglionic sympathetic fibers in the sciatic nerve (see Discussion).

Since the rate of axonal transport of CGRP measured in the sciatic nerve (Fig. 5) does not reflect transport rates of CGRP

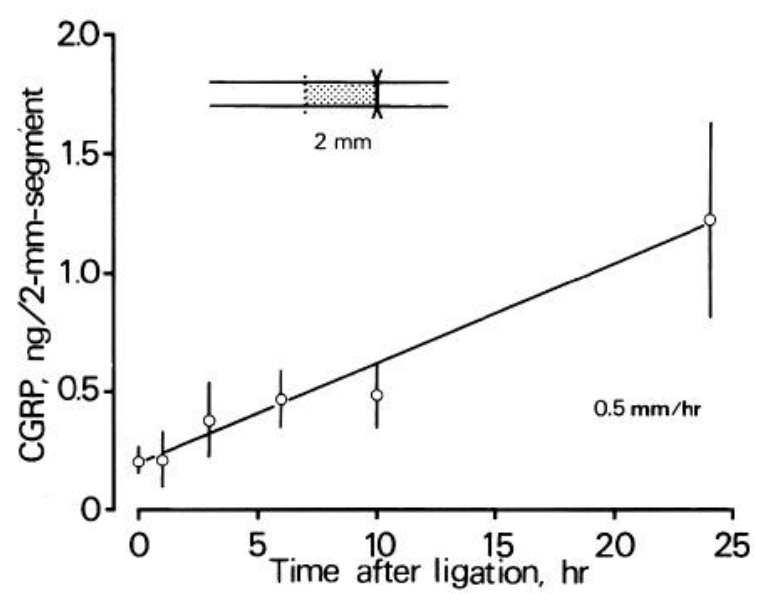

Figure 5. Changes in the amount of CGRP accumulated in the 2-mm segment immediately central to the ligature applied to the sciatic nerve as a function of time after ligation. Vertical bars indicate $\mathrm{SD}(n=5)$. The mean CGRP content at time 0 was measured in $2-\mathrm{mm}$ segments of 7 intact sciatic nerves. 


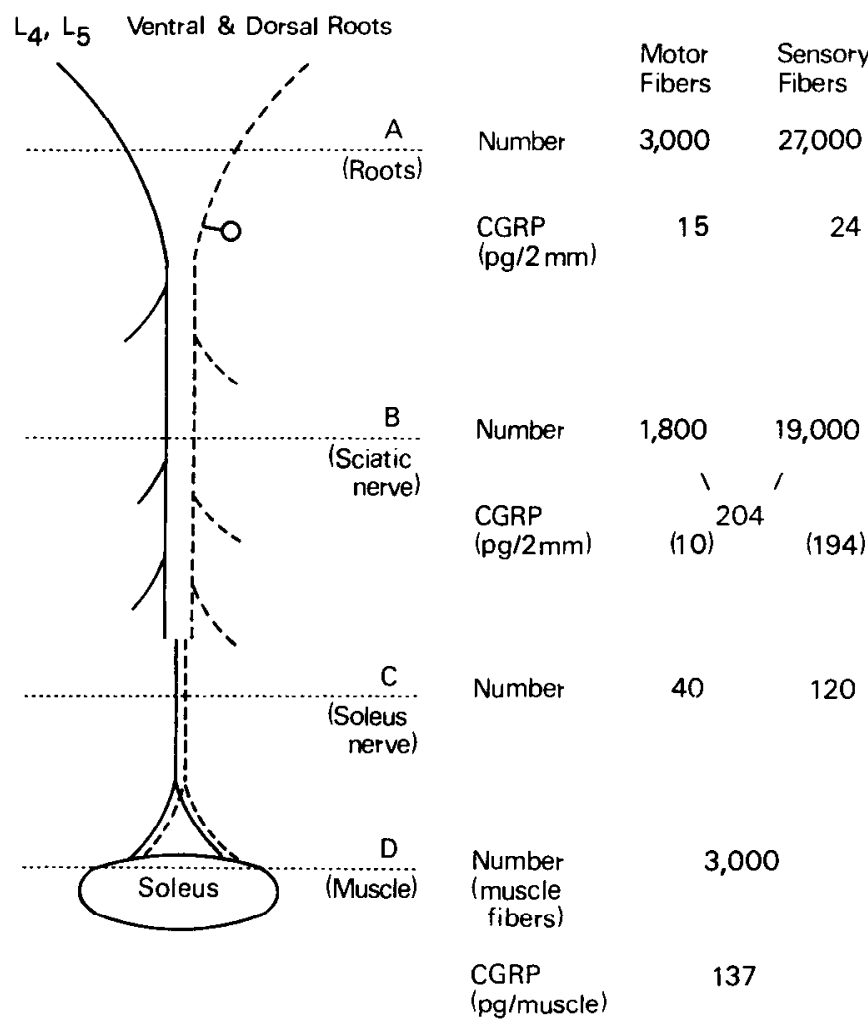

Figure 6. Distributions of CGRP at different levels of the peripheral nerve in relation to the number of motor or sensory fibers. Solid lines indicate motor nerve fibers. Interrupted lines indicate sensory fibers. The numbers of nerve or muscle fibers are quoted or estimated from published reports.

in motor nerve fibers, we also measured CGRP accumulated in ligated ventral roots. As shown in Figure $7 B, 24 \mathrm{hr}$ after ligation, the mean amount of CGRP in a $2-\mathrm{mm}$ segment of the 4 th and 5 th ventral roots increased to $161 \pm 22 \mathrm{pg}(n=5)$ in the scgmcnt immediately central to the ligature. The rate of CGRP transport estimated in the ventral roots $(0.9 \mathrm{~mm} / \mathrm{hr}$; Fig. $7 B)$ was comparable to that observed in the sciatic nerve (Fig. 5).

\section{CGRP content in muscle}

Although individual muscles of the hind leg are innervated by only a small fraction of the motor and sensory nerve fibers in the sciatic nerve, CGRP may be detected in each muscle if it is highly concentrated in the nerve terminals. In fact, the mean CGRP content was found to be $87 \pm 17 \mathrm{pg}$ in the extensor digitorum longus muscle $(n=5)$ and $137 \pm 36 \mathrm{pg}$ in the soleus muscle $(n=5$; Fig. $6 D)$. Seven to $9 \mathrm{~d}$ after section of the sciatic nerve (denervation), the CGRP content in the soleus muscle decreased to $7 \pm 5 \mathrm{pg}(n=4)$, ranging from $0(<2 \mathrm{pg})$ to $14 \mathrm{pg}$. Therefore, it seems clear that the majority of CGRP observed in the intact soleus muscle originates from ncural tissue.

\section{Discussion}

The present results have shown that endogenous CGRP is transported in the somatofugal direction in the peripheral nerve and that CGRP present in muscle originates largely, if not entirely, from neural tissue. Therefore, CGRP must be synthesized in neuron cell bodies and transported to their nerve terminals, where this peptide is highly concentrated. The rate of transport
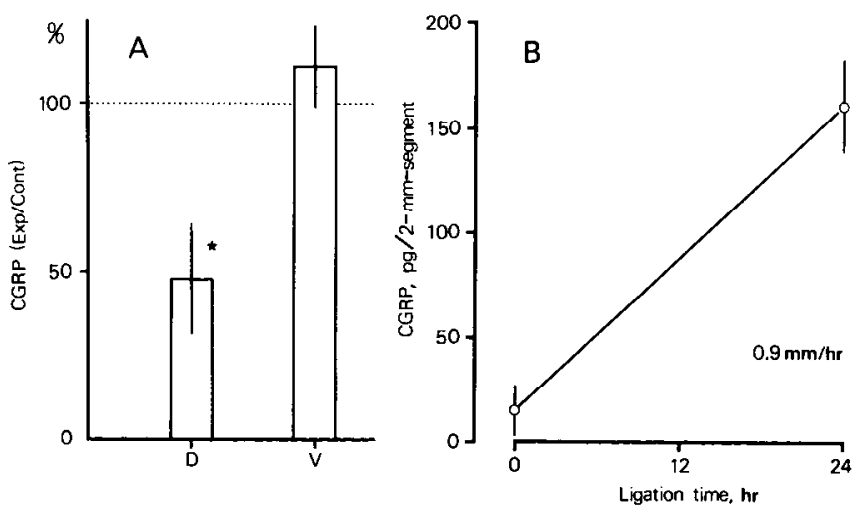

Figure 7. CGRP contents in the sciatic nerve after degeneration of sensory or motor fibers $(A)$ and in the lumbar ventral roots $(B) . A$, The amount of CGRP measured on the experimental side relative to that observed on the contralateral, control side. There was a significant (asterisk) reduction $(D)$ in CGRP content on the experimental side after removal of the lumbar dorsal root ganglia. There was no significant change $(V)$ in CGRP content on the experimental side after section of the lumbar ventral roots. $B$, CGRP contents in the lumbar ventral roots without ligation (at time 0 ) and $24 \mathrm{hr}$ after ligation. Vertical bars indicate $\mathrm{SD}(n=5)$

was estimated to be about $1 \mathrm{~mm} / \mathrm{hr}(0.5-0.9 \mathrm{~mm} / \mathrm{hr})$. This was comparable to the rate of CGRP transport recently evaluated for the autonomic nerve $(0.7-1.5 \mathrm{~mm} / \mathrm{hr}$; Varro et al., 1988).

The majority of CGRP measured in the sciatic nerve appears to derive from the sensory fibers (Fig. $7 A$ ). The rat sciatic nerve at the midthigh level contains approximately 1800 motor fibers (Swett et al., 1986; Schmalbruch, 1986) and 19,000 (including 13,000 unmyelinated fibers) sensory fibers (Schmalbruch, 1986). Thus, the sensory fibers outnumber the motor fibers by about 10 times (Fig. $6 B$ ), and the difference in CGRP content between sensory and motor nerve fibers in the sciatic nerve may be due, at least in part, to their disproportionate ratio in number. However, after removal of the lumbar dorsal root ganglia, the CGRP content in the sciatic nerve on the experimental side was still as high as about $50 \%$ of that on the control side (Fig. $7 \mathrm{~A}$, column $D$ ). Two factors may be considered as possible explanations for this result. First, the dorsal root ganglia might not be removed completely because of enclosure of the ganglion and the ventral root by a common connective sheath (Schmalbruch, 1986). Second, the rat sciatic nerve contains about 6000 sympathetic fibers (Schmalbruch, 1986), which should remain intact following chronic removal of the lumbar dorsal root ganglia or section of the ventral roots. Matteoli et al. (1988) observed a dense network of CGRP-positive varicose fibers around blood vessels in muscle. Thus, some CGRP measured in the sciatic nerve may originate from the sympathetic fibers. The test of this possibility is now under way.

Figure 6 summarizes the CGRP contents measured at different levels of the peripheral nerve in relation to the numbers of motor and sensory fibers. Although the CGRP content in motor fibers of the sciatic nerve was not directly measured, this may be estimated to be about $10 \mathrm{pg} / 2-\mathrm{mm}$ segment (Fig. $6 B$ ) from the ratio of the number of motor fibers in the sciatic nerve (1800; Swett et al., 1986; Schmalbruch, 1986) to that in the ventral roots (3000; Schmalbruch, 1984). The CGRP content in the lumbar dorsal roots $(24 \mathrm{pg} / 2 \mathrm{~mm}$ ), which contain about 27,000 sensory fibers (Schmalbruch, 1987; Fig. 6A), was substantially lower than the value expected from the CGRP content in the 
sciatic nerve (204 pg/2 mm), which contains 19,000 sensory fibers (Schmalbruch, 1986). As described previously, about 50\% of CGRP measured in the sciatic nerve might originate from sympathetic nerve fibers. However, even if this possibility is taken into consideration, the CGRP content per fiber appears to be about 5 times lower in the dorsal root than in the peripheral processes of the sensory neurons. In fact, this is in good agreement with previous observations that the amount of proteins carried by fast axonal transport is 3-5 times lower in the central processes of dorsal root ganglion cells than in their peripheral processes (Komiya and Kurokawa, 1978; Ochs, 1982).

The majority (95\%) of CGRP measured in skeletal muscle was of neural tissue in origin. However, the CGRP content in muscle was remarkably higher than that expected from the number of innervating fibers. The rat soleus muscle, for example, is innervated by only $28 \alpha$-motoneurons (Miyata, 1984) and 12 $\gamma$-motoneurons (Gottschall et al., 1980; Nicolopoulos-Stournaras and Iles, 1983), in addition to about 120 sensory fibers (Fig. 6C; estimated from the ratio of total to motor axonal numbers for the rat medial gastrocnemius nerve) (Jenq et al., 1984; Kashihara et al., 1987). Yet its CGRP content was about $137 \mathrm{pg}(67 \%$ of the CGRP content in a $2-\mathrm{mm}$ segment of the sciatic nerve). Therefore, CGRP in the muscle must be accumulated highly in ncrve terminals. By rough calculation, the amount of CGRP per unit length in nerve terminals may be estimated to be $20-30$ times higher than that in nerve fibers. However, it is not known if the degree of CGRP accumulation in terminals differs among motor, sensory, and sympathetic nerve fibers.

CGRP appears to be localized in large, dense-core vesicles of motor nerve terminals (Matteoli et al., 1988). Also, CGRP immunoreactivity as well as large, dense-core vesicles have been found to be still present even after depletion of ACh quanta and small clear vesicles by $\alpha$-latrotoxin isolated from black widow spider venom (Matteoli et al., 1988). Therefore, if CGRP were released from motor nerve terminals, its release would depend on a mechanism different from that involved in the release of ACh. Detailed studies on the release mechanism of CGRP are required in relation to several trophic actions suggested for this peptide at neuromuscular junctions (see Introduction).

\section{References}

Amara, S. G., V. Jonas, M. G. Rosenfeld, E. S. Ong, and R. M. Evans (1982) Alternative RNA-processing in calcitonin gene expression generates mRNAs encoding different polypeptide products. Nature 298: 240-244.

Cadieux, A., D. R. Springall, P. K. Mulderry, J. Rodrigo, M. A. Ghatei, G. Terenghi, S. R. Bloom, and J. M. Polak (1986) Occurrence, distribution and ontogeny of CGRP immunoreactivity in the rat lower respiratory tract: Effect of capsaicin treatment and surgical denervation. Neuroscience 19:605-627.

Changeux, J. P., A. Devillers-Thiery, J. Riraudat, M. Dennis, T. Heidmann, F. Revah, C. Mulle, O. Heidmann, A. Klarsfeld, B. Fontaine, E. Kordeli, and J. Cartaud (1987) The acetylcholine receptor: Functional organization and evolution during synapse formation. In Strategy and Prospects in Neuroscience, O. Hayaishi, ed., pp. 29-76, Japan Scientific Soc. Press, Tokyo.

Eusebi, F., D. Farini, F. Grassi, L. Monaco, and F. Ruzzier (1988) Effects of calcitonin gene-related peptide on synaptic acetylcholine receptor-channels in rat muscle fibres. Proc. R. Soc. Lond. [Biol.] 234: 333-342.

Fontaine, B., A. Klarsfeld, T. Hökfelt, and J. P. Changeux (1986) Calcitonin gene-related peptide, a peptide present in spinal cord motoneurons, increases the number of acetylcholine receptors in primary cultures of chick embryo myotubes. Neurosci. Lett. 71: 59-65.

Fontaine, B., A. Klarsfeld, and J. P. Changeux (1987) Calcitonin gene- related peptide and muscle activity regulate acetylcholine receptor $\alpha$-subunit mRNA levels by distinct intracellular pathways. J. Cell Biol. 105: 1337-1342.

Furukawa, S., I. Kamo, Y. Furukawa, S. Akazawa, E. Satoyoshi, K. Itoh, and K. Hayashi (1983) A highly sensitive enzyme immunoassay for mouse nerve growth factor. J. Neurochem. 40: 734-744.

Gibson, S. J., J. M. Polak, S. R. Bloom, I. M. Sabate, P. M. Mulderry, M. A. Ghatei, G. P. McGregor, J. F. B. Morrison, J. S. Kelly, R. M. Evans, and M. G. Rosenfeld (1984) Calcitonin gene-related peptide immunoreactivity in the spinal cord of man and of eight other species. J. Neurosci. 4: 3101-3111.

Gottschall, J., W. Neuhuber, M. Muntener, and A. Mysicka (1980) The area cervicalis and infrahyoid muscle of the rat. II. Motor and sensory neurons. Anat. Embryol. 159: 59-69.

Hopfield, J. F., D. W. Tank, P. Greengard, and R. L. Huganir (1988) Functional modulation of the nicotinic acetylcholine receptor by tyrosine phosphorylation. Nature 336: 677-680.

Jenq, C. B., C. E. Ilulsebosch, R. E. Coggeshall, and R. Perez-Polo (1984) The effects of nerve growth factor and its antibodies on axonal numbers in the medial gastrocnemius nerve of the rat. Brain Res. 299: 9-14.

Ju, G., T. Hökfelt, E. Brodin, J. Fahrenkrug, J. A. Fischer, P. Frey, R. P. Elde, and J. C. Brown (1987) Primary sensory neurons of the rat showing calcitonin gene-related peptide immunoreactivity and their relation to substance $\mathbf{P}_{-}$, somatostatin-, gelanin-, vasoactive intestinal polypeptide- and cholecystokinin-immunoreactive ganglion cells. Cell Tissue Res. 247: 417-431.

Kashihara, Y., M. Kuno, and Y. Miyata (1987) Cell death of axotomized motoneurones in neonatal rats, and its prevention by peripheral reinnervation. J. Physiol. (Lond.) 386: 135-148.

Kawai, Y., K. Takami, S. Shiosaka, P. C. Emson, C. J. Hillyard, S. Girgis, I. MacIntyre, and M. Tohyama (1985) Topographic localization of calcitonin gene-related peptide in the rat brain: An immunohistochemical analysis. Neuroscience 15: 747-763.

Kobayashi, H., K. Hashimoto, S. Uchida, J. Sakuma, K. Takami, M. Tohyama, F. Izumi, and H. Yoshida (1987) Calcitonin gene-related peptide stimulates adenylate cyclase activity in rat striated muscle. Experientia 43: 314-316.

Komiya, Y., and M. Kurokawa (1978) Asymmetry of protein transport in two branches of bifurcating axons. Brain Res. 139: 354-358.

Korsching, S., and H. Thoenen (1983) Nerve growth factor in sympathetic ganglia and corresponding target organs of the rat: Correlation with density of sympathetic innervation. Proc. Natl. Acad. Sci. USA 80: 3513-3516.

Kurobe, M., N. Tokida, S. Furukawa, K. Ito, and K. Hayashi (1985) A highly sensitive cnzyme immunoassay (EIA) system for mouse epidermal growth factor (mEGF). Biochem. Intn. 11: 825-832.

Kurobe, M., N. Tokida, S. Furukawa, E. Ishikawa, and K. Hayashi (1986) Development of a sensitive enzyme immunoassay for human epidermal growth factor (Urogastrone). Clin. Chim. Acta 156:51-60.

Laufer, R., and J. P. Changeux (1987) Calcitonin gene-related peptide elevates cyclic AMP levels in chick skeletal muscle: Possible neurotrophic role for a coexisting neuronal messenger. EMBO J. 6: 901906.

Matteoli, M., C. Haimann, F. Torri-Tarelli, J. M. Polak, B. Ceccarelli, and P. De Camilli (1988) Differential effect of $\alpha$-latrotoxin on exocytosis from small synaptic vesicles and from large dense-core vesicles containing calcitonin gene-related peptide at the frog neuromuscular junction. Proc. Natl. Acad. Sci. USA 85: 7366-7370.

Miyata, Y. (1984) Specific terminal elimination at neuromuscular junctions during postnatal development. In Neuronal Growth and Plasticity, M. Kuno, ed., pp. 80-95, Japan Scientific Soc. Press, Tokyo.

Mulle, C., P. Benoit, C. Pinset, M. Koa, and J. P. Changeux (1988) Calcitonin gene-related peptide enhances the rate of desensitization of the nicotinic acetylcholine receptor in cultured mouse muscle cells. Proc. Natl. Acad. Sci. USA 85: 5728-5732.

New, H. V., and A. W. Mudge (1986) Calcitonin gene-related peptide regulates muscle acetylcholine receptor synthesis. Nature 323: 809811 .

Nicolopoulos-Strournaras, S., and J. F. Iles (1983) Motor neuron columns in the lumbar spinal cord of the rat. J. Comp. Neurol. 217: 7585.

Ochs, S. (1982) Axoplasmic Transport and Its Relation to Other Nerve Functions, Wiley, New York.

Rodrigo, J., J. M. Polak, G. Terenghi, C. Cervantes, M. A. Ghatei, P. 
K. Mulderry, and S. R. Bloom (1985) Calcitonin gene-related peptide (CGRP)-immunoreactive sensory and motor nerves of the mammalian palate. Histochemistry 82: 67-74.

Rosenfeld, M. G., J. J. Mermod, S. G. Amara, L. W. Swanson, P. E. Saechenko, J. Rivier, W. W. Vale, and R. M. Evans (1983) Production of a novel neuropeptide encoded by the calcitonin gene via tissue-specific RNA processing. Nature 304: 129-135.

Schmalbruch, H. (1984) Motoneuron death after sciatic nerve section in newborn rats. J. Comp. Neurol. 224: 252-258.

Schmalbruch, H. (1986) Fiber composition of the rat sciatic nerve. Anat. Rec. 215: 71-81.

Schmalbruch, H. (1987) The number of neurons in dorsal root ganglia L4-L6 of the rat. Anat. Rec. 219: 315-322.

Swett, J. E., R. P. Wikholm, R. H. I. Blanks, A. L. Swett, and L. C. Conley (1986) Motoneurons of the rat sciatic nerve. Exp. Neurol. 93: 227-252.

Takami, K., Y. Kawai, S. Shiosaka, Y. Lee, S. Girgis, C. J. Hillyard, I. MacIntyre, P. C. Emson, and M. Tohyama (1985a) Immunohistochemical evidence for coexistence of calcitonin gene-related peptide- and choline acetyltransferase-like immunoreactivity in neurons of the rat hypoglossal, facial and ambiguus nuclei. Brain Res. 328: 386-389.
Takami, K., Y. Kawai, S. Uchida, M. Tohyama, Y. Shiotani, H. Yoshida, P. C. Emson, S. Girgis, C. J. Hillyard, and I. MacIntyre (1985b) Effect of calcitonin gene-related peptide on contraction of striated muscle in the mouse. Neurosci. Lett. 60: 227-230.

Takami, K., K. Hashimoto, S. Uchida, M. Tohyama, and H. Yoshida (1986) Effect of calcitonin gene-related peptide on the cyclic AMP level and contraction of isolated mouse diaphragm. Jpn. J. Pharmacol. 42: $345-350$.

Tsujimoto, T., and M. Kuno (1988) Calcitonin gene-related peptide prevents disuse-induced sprouting of rat motor nerve terminals. J. Neurosci. 8: 3951-3957.

Varro, A., T. Green, S. Holmes, and G. J. Dockray (1988) Calcitonin gene-related peptide in visceral afferent nerve fibres: Quantification by radioimmunoassay and determination of axonal transport rates. Neuroscience 26: 927-932.

Wiesenfield-Hallin, T., T. Hökfelt, J. M. Lundberg, W. G. Forssmann, M. Reinecke, P. Tschopp, and J. Fischer (1984) Immunoreactive calcitonin gene-related peptide and substance $P$ coexist in sensory neurons to the spinal cord and interact in spinal behavioral responses of the rat. Neurosci. Lett. 52: 199-204.

Zaidi, M., L. H. Breimer, and I. MacIntyre (1987) Biology of peptides from the calcitonin genes. Q. J. Exp. Physiol. 72: 371-408. 